\title{
Population genetic characterization and family reconstruction in brood bank collections of the Indian major carp Labeo rohita (Cyprinidae:Cypriniformes)
}

\author{
Ashraf Ullah, Abhisak Basak, Md. Nazrul Islam and Md. Samsul Alam*
}

\begin{abstract}
The founder stock of a captive breeding program is prone to changes in genetic structure due to inbreeding and genetic drift. Genetic characterization of the founder population using suitable molecular markers may help monitor periodic changes in the genetic structure in future. To develop benchmark information about the genetic structure we analyzed six microsatellite loci in the Brodbank collections of rohu (Labeo rohita) originated from three major rivers - the Jamuna, the Padma and the Halda. A total of 28 alleles were detected in 90 individuals with an average of 4.6 alleles per locus. The average observed heterozygosity ranged from 0.655 to 0.705 and the expected heterozygosity ranged from 0.702 to 0.725 . The mean $F_{/ 5}$ values were $0.103,0.106$ and 0.018 for the Jamuna, Padma and Halda fishes respectively. The population pair-wise $F_{S T}$ values ranged from 0.0057 to 0.0278 . Structure analysis grouped the fishes of the three rivers into two clusters. The numbers of half-sib families were 5,5 and 4 and the numbers of full-sib families were 12, 10 and 18 for the Halda, Jamuna and the Padma samples respectively. Bottleneck was detected in all the river samples. We recommend to collect more fish from different locations of the major rivers to broaden the genetic variability of the founder stocks of the Brood bank.
\end{abstract}

Keywords: Microsatellite, Genetic variation, Major carps, Brood bank, Bottleneck, Sib-ship

\section{Background}

Labeo rohita (Hamilton), a member of the Indian major carps group of the family Cyprinidae is naturally distributed in the rivers of Bangladesh, India, Pakistan and Myanmar (Talwar and Jhingran 1991). The column feeder rohu (L. rohita), along with the surface feeder catla, Catla catla (Hamilton) and bottom feeder mrigal, Cirrhinus cirrhosus (Hamilton) constitutes an important and popular aquaculture practice in the region named carp polyculture system. L. rohita is the highest contributing single species in aquaculture production of Bangladesh sharing $22.0 \%$ of the country's pond production (FRSS 2012). The world aquaculture production of L. rohita was 1.17 million MT in 2010 approximately $2 \%$ of the total

*Correspondence: samsul.alam@bau.edu.bd

Department of Fisheries Biology and Genetics, Bangladesh Agricultural University, Mymensingh 2202, Bangladesh aquaculture production that ranked 11th in the list of principal contributing species (FAO 2012).

Aquaculture in Bangladesh has experienced a steady growth of about $6 \%$ since 1984/85 until present due to horizontal expansion as well as intensification and contributing more than $50 \%$ to the total fish production of the country (FRSS 2012). Cheap and simple spawn production technology and attractive margin led to establishment of some 900 carp hatcheries in the country over the decades. However, hatcheries engaged in production of carp spawn are reported not to be managed properly due to multiple factors such as lack of awareness about the negative consequences of improper management, lack of technical knowledge, lack of facilities for maintaining required number of quality breeders and overall high competition in the fish seed market. Use of smaller size breeders (negative selection), inbreeding and hybridization have been common practices in the hatcheries 
that are individually or collectively responsible for the deterioration of fish seed quality in the country (Hussain and Mazid 2002; Simonsen et al. 2005).

In an attempt to restoring quality of the hatchery produced seed, the Department of Fisheries (DoF), Government of Bangladesh initiated a Brood Bank Establishment project for the three Indian major carps species in 2008. The objective of the project is to ensure supply of good quality juvenile brood to the hatcheries to develop broodstock. The founder stocks of the broodbank were developed by collecting spawn of Labeo rohita, Catla catla and Cirrhinus cirrhosus from three major river sourcesthe Halda, the Jamuna, and the Padma. These three rivers have been identified as the spawning ground of the Indian major carps. The collected spawn were randomly distributed among 20 Government owned fish seed multiplication farms across the country and maintained following standard nursing and rearing protocols. The fishes, upon grown up, have been introduced in the induced breeding program of the Government hatcheries for the last few years for multiplication and dissemination.

Genetic variation is important in maintaining the evolutionary potential and fitness of a population (Vandewoestijne et al. 2008). The founder stocks of the hatcheries are finite and are prone to inbreeding and genetic drift- two potential features that can destroy the genetic variability of the hatchery populations over time. Thus, maintenance of genetic variation is the most important concern for the hatchery stock management. The level of success in the hatchery management and also the status of the hatchery brood stock can be assessed by comparing the genetic variability of the hatchery stock with that of a reference natural stock or preferably of the base population (Hansen et al. 2000). Therefore, in order to allow monitoring of the genetic quality of the hatchery stocks in future, it is recommended that the genetic structure of the base population (e.g. Brood bank population) be analyzed with an appropriate molecular marker and the information is archived. Microsatellites, defined as loci of short DNA (2-6 bp) sequences arranged in tandem repeats (simple sequence repeats, SSR) and distributed randomly throughout the genome (Tautz 1989), have been recognized as highly polymorphic markers suitable for genetic characterization and applicable in many studies of ecology, evolution and conservation (O'Connell and Wright 1997; Hansen and Jensen 2005; AbdulMuneer 2014). Molecular marker-based genotyping can also be used for assessing family relationships and genetic relatedness among individuals of a population. These information have practical implications in behavioral ecology as well as population and conservation genetics (Blouin 2003); and are particularly important for breeding programs (Hansen and Jensen 2005). Several sets of microsatellite DNA markers have been isolated from $L$. rohita (Das et al. 2005; Sahoo et al. 2014) and used for genetic analysis (Alam et al. 2009). The objective of the study was to reveal the population genetic structure and relationship among $L$. rohita of the Jamuna, Padma and the Halda rivers maintained under the Brood Bank of the Department of Fisheries.

\section{Materials}

\section{Sample collections and extraction of genomic DNA}

We collected $L$. rohita brood fish of approximately 2-years-old in July 2010 from three broodstocks maintained under the Brood Bank of the Department of Fisheries, Government of Bangladesh. The broodstocks were developed from spawn of the three major rivers- the Jamuna, the Padma, and the Halda. The Jamuna stock was maintained in Shambhugonj Farm (Mymensingh) $(\mathrm{n}=500)$, the Padma stock was maintained in Rajshahi Farm $(n=500)$ and the Halda stock was maintained Jangalia Farm (Comilla) $(\mathrm{n}=400)$. A small clip from the caudal fin of 30 randomly selected fish of each of the three river sources was collected and immediately preserved in $95 \%$ ethanol until used for isolation of genomic DNA.

We extracted genomic DNA using the standard proteinase-K digestion, phenol: chloroform: isoamyl alcohol extraction and alcohol precipitation method as described in Islam and Alam (2004). DNA quantity was measured using a spectrophotometer (BioPhotometer plus, Eppendorf, Germany).

\section{Microsatellite genotyping}

For genetic diversity analysis, we used six pairs of microsatellite primers (Lr1, Lr3, Lr6, Lr12, Lr14b and Lr21) developed from $L$. rohita by Das et al. (2005). The primers were selected based on the number of alleles and polymorphic information content. PCR reaction contained $50 \mathrm{ng}$ template DNA, $0.25 \mu \mathrm{M}$ of each primer, $0.25 \mathrm{mM}$ of each of the dNTPs, $1.5 \mu \mathrm{l} 10 \times$ reaction buffer containing $1.5 \mathrm{mM} \mathrm{MgCl}{ }_{2}$ and one unit of Taq DNA polymerase in a total volume of $15 \mu \mathrm{l}$. PCR amplifications were performed in a gradient thermal cycler (Master Cycler Gradient, Eppendorf, Germany) with the following temperature profile: $3 \mathrm{~min}$ initial denaturation at $94{ }^{\circ} \mathrm{C}$ followed by 35 cycles, each of $30 \mathrm{~s}$ at $94{ }^{\circ} \mathrm{C}, 30 \mathrm{~s}$ at respective annealing temperature and $1 \mathrm{~min}$ at $72^{\circ} \mathrm{C}$. Finally, an additional one cycle of $7 \mathrm{~min}$ at $72{ }^{\circ} \mathrm{C}$ was added to allow complete elongation of the amplified products. For genotyping, the PCR products were separated on $6 \%$ denaturing polyacrylamide gel containing 19:1 acrylamide:bis-acrylamide and $6 \mathrm{M}$ urea using a Sequi Gen GT sequencing electrophoresis system (BIO-RAD Laboratories, Hercules, CA, USA) and visualized by staining with silver nitrate following the Promega (Madison,WI) protocol. The stained gel 
plates were scanned and saved in GPEG format and the bands representing particular alleles at the microsatellite loci were scored based on the sizes estimated by the AlphaEase FC, 1D gel image analysis software.

\section{Statistical analysis of microsatellite data}

The genotype data comprising the six microsatellite loci of 90 fish from three populations were subjected to test for null alleles and large allele dropouts or stutter-bands using the software MicroChecker (van Oosterhout et al. 2004). We estimated the polymorphic information content (PIC) for each locus in the complete set of samples using the software CERVUS version 3.0.3 (Kalinowski et al. 2007). As measures of genetic variability in the three populations at six loci, we estimated the population-wise allelic richness $(A r)$, observed heterozygosity $(\mathrm{Ho})$ and expected heterozygosity $(\mathrm{He})(\mathrm{Nei} 1987)$ at each locus by the software FSTAT 2.9.3.2 (Goudet 2001). The exact $p$ value for deviation from Hardy-Weinberg expectation at each locus was estimated by the Markov chain method (Guo and Thompson 1992) implemented in the software GENEPOP 4.0 (Rousset 2008) with the following parameters: Dememorization-10000, batches- 1000 and iterations per batch- 10000. The software FSTAT (Goudet 2001) was used for calculating the pair-wise $F_{S T}$ (Weir and Cockerham 1984) values by means of 10,000 permutations of genotypes. The $95 \%$ confidence interval for each pair-wise $F_{S T}$ was calculated by bootstrapping on loci with 1000 replications. For all multiple comparisons, the global significance level (0.05) was subjected to sequential Bonferroni corrections (Rice 1989).

For inferring the number of sub-populations, the software STRUCTUE 2.3.2 (Pritchard et al. 2000; Falush et al. 2003) was used with a burn in length of 50,000 and MCMC (Monte-Carlo Markov Chain) iterations of 500,000 . Five independent runs were performed for each $\mathrm{k}$ value, ranging from 1 to 5 . The website based program STRUCTURE HARVESTER (Earl and vonHoldt 2012) was used for determining the number of clusters according to Evanno et al. (2005). We examined the evidence for genetic bottlenecks in each population using the software BOTTLENECK version 1.2.02 (Cornuet and Luikart 1996) under the infinite allele model (IAM), two-phase model (TPM) and stepwise-mutation model (SMM) with 1000 replications.

We reconstructed half- and full-sib families without information on parental genotypes as per maximum likelihood method implemented in the software COLONY 2 (Jones and Wang 2010). A tentative $2.5 \%$ error rate was assumed for all loci, both for allelic dropouts and erroneous sizing of alleles. We compared the family configuration of each sample with that of a sample of the same number $(\mathrm{n}=30)$ of unrelated individuals simulated from the empirical allele frequency data by using the HYBRIDLAB v 1.0 program (Nielsen et al. 2006). Hansen and Jensen (2005) inference was followed for significance in family reconstruction: the sibship reconstruction of a sample was considered 'significant' if the number of halfand full-sib families was lower in the real samples compared to the samples of simulated unrelated individuals and if there were more individuals in one or more of the full-sib families generated from real individuals than were observed in any of the full-sib 'families' generated from the simulated unrelated individuals.

\section{Results}

\section{Genetic diversity within population and deviations from Hardy-Weinberg expectation}

A total of 28 alleles were detected at six microsatellite loci in the three rohu populations. Examination of genotyping errors using MicroChecker revealed no evidence for null alleles and large allele dropout or stutter-band scoring at any of the six loci. The number of alleles ranged from three $(L r 14 b)$ to six ( $L r 1$ and $L r 21)$ with an average of 4.66 alleles per locus (Table 1). All six microsatellite loci analyzed in the samples of three river populations were found to be polymorphic $\left(P_{95}\right)$ and the polymorphic information contents ranged from 0.646 to 0.808 .

The observed heterozygosity $(\mathrm{Ho})$ ranged from 0.500 to 0.833 and the expected heterozygosity $(\mathrm{He})$ ranged from 0.598 to 0.808 (Table 1 ). The average observed heterozygosity in the Halda population $(\mathrm{Ho}=0.705)$ and the average expected heterozygosity of the Padma population $(\mathrm{He}=0.725)$ were slightly higher than those of the other two populations. The $F_{I S}$ values ranged from -0.098 to 0.359; the mean $F_{I S}$ values for the Jamuna, Padma and the Halda populations were $0.103 \pm 0.158,0.106 \pm 0.165$ and $0.018 \pm 0.154$ respectively. Significant deviations from Hardy-Weinberg Expectation (HWE) were detected in 11 of the 18 tests (Table 1). The Jamuna and the Halda population deviated at four loci each and the Padma population deviated at three loci.

\section{Population structure, population differentiation and genetic distance}

We obtained consistent results across the five independent runs for each $\mathrm{k}$ value $(\mathrm{k}=1-5)$. The mean estimated log-likelihood value was found to be the highest for $k=2$ (Fig. 1a). Delta k, the quantity of the second order rate of change of the likelihood function estimated by the method of Evanno et al. (2005) was also highest for $\mathrm{k}=2$ (Fig. 1b). The pair-wise population differentiation $\left(F_{S T}\right)$ value between the Padma and the Halda population was the highest $(0.0278)$ and that between the Halda and the Jamuna population was the lowest $(0.0057)$ (Table 2). The $F_{S T}$ values between the Halda-Padma and 
Table 1 Genetic variation in three populations of $L$. rohita

\begin{tabular}{|c|c|c|c|c|c|c|}
\hline \multirow[t]{2}{*}{ Locus } & \multirow[t]{2}{*}{ Allele sizes (bp) } & \multirow[t]{2}{*}{ PIC } & \multirow[t]{2}{*}{ Parameters } & \multicolumn{3}{|l|}{ Population } \\
\hline & & & & Jamuna & Padma & Halda \\
\hline \multirow[t]{5}{*}{$L r 1$} & $140-164$ & 0.776 & $\operatorname{Ar}$ & 6.000 & 5.000 & 6.000 \\
\hline & & & Ho & 0.833 & 0.600 & 0.733 \\
\hline & & & $\mathrm{He}$ & 0.808 & 0.762 & 0.685 \\
\hline & & & $F_{15}$ & -0.014 & 0.229 & -0.007 \\
\hline & & & HWEP & $0.0001^{*}$ & $0.0000^{*}$ & $0.0001^{*}$ \\
\hline \multirow[t]{5}{*}{ Lr3 } & $142-166$ & 0.754 & Ar & 5.000 & 5.000 & 5.000 \\
\hline & & & Ho & 0.500 & 0.633 & 0.767 \\
\hline & & & $\mathrm{He}$ & 0.762 & 0.742 & 0.733 \\
\hline & & & $F_{15}$ & 0.359 & 0.163 & -0.029 \\
\hline & & & HWEP & $0.0000^{*}$ & $0.0000^{*}$ & $0.0000^{*}$ \\
\hline \multirow[t]{5}{*}{ Lr6 } & $138-154$ & 0.747 & $\operatorname{Ar}$ & 4.000 & 4.000 & 4.000 \\
\hline & & & Ho & 0.600 & 0.533 & 0.567 \\
\hline & & & $\mathrm{He}$ & 0.736 & 0.740 & 0.741 \\
\hline & & & $F_{15}$ & 0.201 & 0.295 & 0.285 \\
\hline & & & HWEP & $0.0033^{*}$ & $0.0045^{*}$ & $0.0035^{*}$ \\
\hline \multirow[t]{5}{*}{$\operatorname{Lr} 12$} & 148-178 & 0.705 & Ar & 4.000 & 4.000 & 4.000 \\
\hline & & & Ho & 0.700 & 0.833 & 0.800 \\
\hline & & & $\mathrm{He}$ & 0.662 & 0.727 & 0.691 \\
\hline & & & $F_{15}$ & -0.041 & -0.130 & -0.142 \\
\hline & & & HWEP & $0.3507 N S$ & $0.2827 \mathrm{NS}$ & $0.0069 *$ \\
\hline \multirow[t]{5}{*}{ Lr14b } & 184-192 & 0.646 & Ar & 3.000 & 3.000 & 3.000 \\
\hline & & & Ho & 0.567 & 0.667 & 0.667 \\
\hline & & & $\mathrm{He}$ & 0.643 & 0.620 & 0.598 \\
\hline & & & $F_{15}$ & 0.135 & -0.058 & -0.098 \\
\hline & & & HWEP & $0.2589 \mathrm{NS}$ & $0.0521 \mathrm{NS}$ & $0.1822 \mathrm{NS}$ \\
\hline \multirow[t]{5}{*}{ Lr21 } & $132-168$ & 0.808 & $\operatorname{Ar}$ & 6.000 & 6.000 & 6.000 \\
\hline & & & Ho & 0.767 & 0.667 & 0.700 \\
\hline & & & $\mathrm{He}$ & 0.738 & 0.761 & 0.764 \\
\hline & & & $F_{15}$ & -0.022 & 0.140 & 0.100 \\
\hline & & & HWEP & $0.0010^{*}$ & $0.0261 \mathrm{NS}$ & $0.0353 \mathrm{NS}$ \\
\hline \multicolumn{3}{|c|}{ Mean $( \pm S D)$ Ar across loci } & & $4.667 \pm 1.211$ & $4.50 \pm 1.048$ & $4.667 \pm 1.211$ \\
\hline \multicolumn{3}{|c|}{ Mean $( \pm S D)$ Ho across loci } & & $0.661 \pm 0.127$ & $0.655 \pm 0.10$ & $0.705 \pm 0.082$ \\
\hline \multicolumn{3}{|c|}{ Mean $( \pm S D)$ He across loci } & & $0.724 \pm 0.061$ & $0.725 \pm 0.053$ & $0.702 \pm 0.059$ \\
\hline \multicolumn{3}{|c|}{ Mean $( \pm S D) F_{15}$ across loci } & & $0.103 \pm 0.158$ & $0.106 \pm 0.165$ & $0.018 \pm 0.154$ \\
\hline
\end{tabular}

PIC Polymorphic information content, Ar Allelic richness, Ho observed heterozygosity, He expected heterozygosity, $F_{I S}$ inbreeding coefficient, $H W E P$ probabilities for Hardy-Weinberg expectation, NS not significant

* Significant after sequential Bonferroni corrections (initial k=3, Rice, 1989)

Jamuna-Padma population pairs were found to be significant $(\mathrm{P}<0.01667)$. The Nei's $(1972)$ genetic distance between the Jamuna and the Padma populations was the highest $(0.128)$ while that between the Jamuna and the Halda population was the lowest (0.062) (Table 2).

\section{Genetic bottlenecks}

For detecting genetic bottlenecks, we applied sign test, Wilcoxon rank test and mode shift tests under IAM, TPM and SMM. Sign test could not detect bottlenecks in any of the three populations $(\mathrm{P}>0.0167)$ while the Wilcoxon sign rank test and the mode-shift test detected recent bottlenecks in all populations under the three mutation models $(\mathrm{P}<0.01667)$ (Table 3$)$.

\section{Family reconstruction}

We reconstructed full-sib and half-sib families using Wang's (2004) method which showed that the number of half-sib families ranged from four (Padma) to five (Halda and Jamuna) and the number of full-sib families ranged 


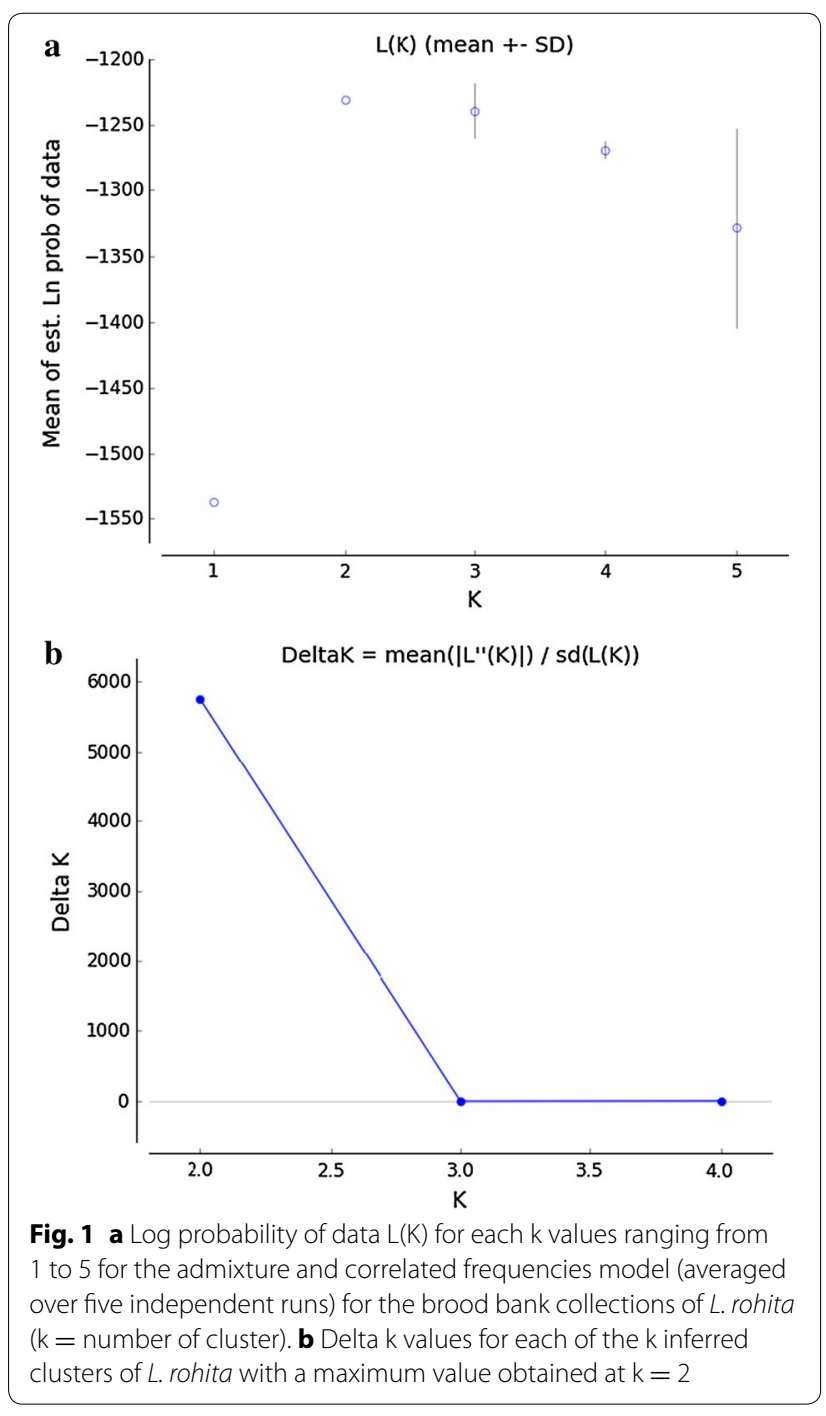

from 10 (Jamuna) to 18 (Padma) (Fig. 2a, c, e). We also reconstructed full- and half-sib families from the same number (\#30) of unrelated individuals simulated from the gene frequency of the original samples to test the significance of family reconstruction according to Hansen and Jensen (2005). The family reconstructions were found to be significant as the numbers of both the half-sib and full-sib families in the simulated samples were higher in all three populations and several of the putative full-sib families of the real samples included far more individuals than were observed in the simulated data (Fig. 2b, d, f). For example, two full-sib families of the Halda and Jamuna and four full-sib families of the Padma samples contained higher number of individuals than the highest value obtained for the corresponding simulated data of the respective population (Fig. 2).

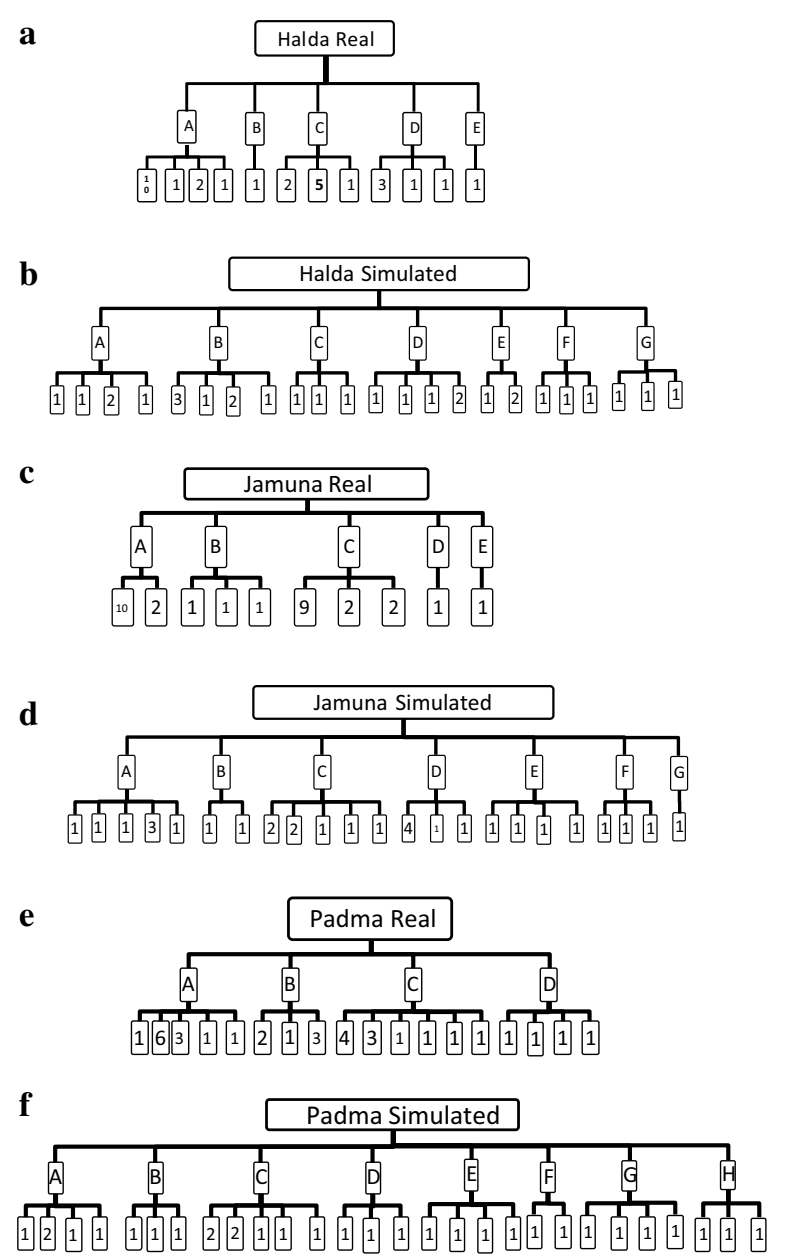

Fig. 2 Results of sibship reconstruction grouping the individuals into full-sib families under the corresponding half-sib families (cluster). The upper hierarchy of the figures denotes the source of the sample, the second hierarchy denotes the half-sib families (cluster) and the third hierarchy denotes individual full-sib families nested within half-sib families. The number of individuals included to each full-sib family is mentioned. a Sibship reconstruction based on real Halda river (HR) individuals, b simulated unrelated $H R$ individuals, c real Jamuna river (JR) individuals, $\mathbf{d}$ simulated unrelated JR individuals, e real Padma river (PR) individuals, $\mathbf{f}$ simulated unrelated PR individuals

\section{Discussion}

Establishing a brood bank for aquaculture species may serve two purposes: preserving the genetic variation of the population by maintaining a large random mating population and supporting genetic improvement programs for important production traits. Maintaining genetic variation is very important because the potentials for genetic improvement and fitness of a population are dependent on the existence of genetic variation. Genetic characterization of the founder population would allow 
Table 2 Above diagonal: pairwise estimates of $F_{S T}$ and their associated $95 \%$ confidence interval $( \pm)$ calculated based on bootstrapping over loci (1000 replications) ( $P$ critical $=0.01667$, after Bonferroni correction)

\begin{tabular}{llll}
\hline Population & Jamuna & Padma & \multicolumn{1}{l}{ Halda } \\
\hline Jamuna & & $0.0255^{*} \pm 0.0015$ & $0.0057 \pm 0.0007$ \\
Padma & 0.128 & & $0.0278^{*} \pm 0.0015$ \\
Halda & 0.062 & 0.124 & \\
\hline
\end{tabular}

Below diagonal: Nei's (1972) genetic distance between population pairs of $L$. rohita

* Significant after sequential Bonferroni corrections (initial k =3)

monitoring of the brood bank stocks in future to assess the impact of captive breeding on the genetic structure.

In the present study, we have characterized six microsatellite loci in L. rohita of the Brood bank stocks collected from three major rivers- the Halda, the Jamuna, and the Padma. The six markers were found to be highly informative as the PICs were $>0.500$ (Botstein et al. 1980) supporting the suitability for analysis of genetic diversity. Using DNA markers, the population genetic structures of these three river populations had also been studied in the past (Islam and Alam 2004; Alam et al. 2009). Islam and Alam (2004) applying six decamer random primers analyzed a total of $140 \mathrm{~L}$. rohita collected from the rivers Jamuna, Padma and Halda and one hatchery while Alam et al. (2009) analyzed 105 fish collected from the same three rivers using four microsatellite markers. However, samples used in all the previous studies were collected randomly and have not been maintained for propagation as a recognized breeding unit.

The objective of establishing the brood bank is to overcome genetic problems and ensure supply of quality brood and fingerlings to be used for aquaculture in the country. If records are maintained about these stocks, the present data could be used to evaluate the changes in genetic parameters of the brood bank stocks of $L$. rohita in future. For evaluating intra-population genetic variation, we analyzed allelic richness, observed heterozygosity, expected heterozygosity and inbreeding coefficient. For inter-population genetic diversity, we analyzed
$F_{S T}$ and genetic distance among population pairs. The observed heterozygosity and expected heterozygosity obtained in the present study were similar to those reported by Sahoo et al. (2014) who analyzing 11 loci in 192 individuals from three rivers and one hatchery stocks reported observed heterozygosity ranging from 0.500 to 0.870 and expected heterozygosity ranging from 0.389 to 878. However, the allelic richness obtained in L. rohita populations in the present study were greater than those reported by Das et al. (2005) who analyzed 12 microsatellite loci (including the six used in the present study) in 18 unrelated fish and Alam et al. (2009) who analyzed four microsatellite loci in 105 fish. Sahoo et al. (2014) observed null alleles at locus Lr-12 however we have not detected null alleles at any of the six loci. In fact, null allele is the result of mutation at the priming site which is completely a random process. Therefore, null alleles may be observed in one population but may not in the others even within the same region.

The present study detected significant deviations from the HWE in $61.11 \%$ cases. Alam et al. (2009) reported significant deviation in HWE in $41.66 \%$ in L. rohita samples of the same three rivers. The observed heterozygosity $\mathrm{Ho}$ ) values were higher than the respective heterozygosity $(\mathrm{He})$ values expected from observed number of alleles at $50.00 \%$ of the loci in the populations indicating the probability of recent severe reduction in effective population size, a phenomenon popularly termed as genetic bottleneck. The tests for genetic bottlenecks under the assumption of mutation drift equilibrium though not conclusive revealed signs of decline of the individuals in all the populations of L. rohita. Bottlenecks were also detected in populations of the other three major carps species Catla catla (Basak et al. 2014), Cirrhinus cirrhosus (Hasanat et al. 2014) and Labeo calbasu (Saha et al. 2010).

The production of major carps in the Padma and the Jamuna river systems in the year 2001-2002 were 187 MT and 157 MT (FRSS 2003) which reduced to only 103 MT and 43 MT respectively in the year 2010-2011 (FRSS 2012). Production of carp spawn in the Halda

Table 3 Results of bottleneck test for three river stocks of L. rohita Broodbank

\begin{tabular}{|c|c|c|c|c|c|c|c|}
\hline \multirow[t]{2}{*}{ Population } & \multicolumn{3}{|c|}{ Sign test } & \multicolumn{3}{|c|}{ Wilcoxon rank test } & \multirow[t]{2}{*}{ Mode shift } \\
\hline & IAM & TPM & SMM & IAM & TPM & SMM & \\
\hline Jamuna & 0.037 & 0.041 & 0.043 & $0.015^{*}$ & $0.015^{*}$ & $0.015^{*}$ & Shifted \\
\hline Padma & 0.033 & 0.041 & 0.043 & $0.015^{*}$ & $0.015^{*}$ & $0.015^{*}$ & Shifted \\
\hline Halda & 0.033 & 0.038 & 0.044 & $0.015^{*}$ & $0.015^{*}$ & $0.015^{*}$ & Shifted \\
\hline
\end{tabular}

The values indicate probability under the hypotheses of mutation drift equilibruim

* Evidence for recent bottlenecks $(P<0.0167)$ (after Bonferroni correction)

Shifted mode of allele frequency indicates occurrence of recent genetic bottlenecks 
river also reduced substantially from $2470 \mathrm{~kg}$ in 1945 to $234 \mathrm{~kg}$ in 2011 with an all-time low of only $20 \mathrm{~kg}$ in 2004 (Azadi and Arshad-ul-Alam 2012). This information testify the reduction in population sizes of the three major river systems recognized as natural breeding grounds of the Indian major carps. Population declines in the rivers may be attributed to many reasons such as overexploitation through destructive fishing (fixed gear across the rivers and use of monofilament gill net), habitat destruction, water pollution and siltation. For the Halda river, it should be taken into consideration whether the recruitment in the river is enough as the spawns are collected intensively every year. A stock assessment program (Rahman 2008) supplemented with thorough genetic characterization involving samples from different location and large number of loci would help evaluate the trend of fish population in the rivers, particularly of the Halda river. It is important because, this bottleneck may result in reduction in genetic variation in near future which will ultimately lead to reduction in adaptability to the fluctuating environmental conditions under the climate change scenario (Vandewoestijne et al. 2008). Taken together the signs of bottleneck revealed by the genetic analysis and the trend of production in the major rivers, management measures should be adopted such as temporary ban on fishing particularly in the breeding season to enhance the fisheries.

The $F_{S T}$ values between different population pairs ranged from 0.0057 to 0.0278 , which indicate that the genetic differentiation among the studied populations is low (Balloux and Lugon-Moulin 2002). Hansen et al. (2006) analyzing seven microsatellite loci also reported weaker differentiation between the Jamuna and the Halda river populations compared to the hatchery populations of catla suggesting strong genetic drift in the hatchery stocks.

The number of individuals genotyped and the number of markers used for genotyping play a role in accurate determination of the number of groups. Evanno et al. (2005) opined that calculating delta k using as low as five microsatellite markers, can allow detection of the real number of groups. Regarding sample sizes for microsatellite-based population genetic studies, Hale et al. (2012) proved that a sample size of 25-30 individuals per population was enough for accurately estimating the allele frequencies and expected heterozygosity in a population. Thus, the number of individuals we genotyped from each population $(\mathrm{n}=30)$ and the number of microsatellite markers we used (six nos.) comply with both the conditions for population genetic analysis.

Inbreeding and genetic drift are two major consequences that may deteriorate the genetic quality of a captive population maintained in a hatchery or a brood bank. No inbreeding was detected in the brood bank stocks of
L. rohita of the three major rivers. However, it may happen when the broods of next generation will be selected. And at the same time care should be taken to avoid any change in gene frequencies due to sampling error, a phenomenon termed as genetic drift. The next generation's broods should be selected in such a way that the alleles with the minimum frequencies in the base population are not lost because once lost, it may be a loss for ever. The lowest frequency of alleles we detected was 0.017. Since, we are discussing about a brood bank collections, a $99 \%$ guarantee should be ensured to save the rare alleles. And if we want to maintain that guarantee for ten generations, the effective number of breeders $(\mathrm{Ne})$ should be at least 344 and for five generations, the Ne should be at least 309 (Tave 1993).

According to Hansen and Jensen (2005), the family reconstruction is considered to be significant if the numbers of families reconstructed from the simulated genotypes were higher than those constructed from original genotype data. Reconstruction of families involving simulated unrelated individuals, based on the allele frequencies of the respective samples, confirmed that much higher numbers of families that include fewer individuals would be expected as compared to the real samples. For instance, the highest number of individuals within a full-sib family in the simulated Halda river (HR) sample was two (Fig. 2b), whereas two full-sib families in the real Halda sample consisted of five and ten individuals (Fig. 2a). Similar trend was also observed in the Jamuna and Padma samples. The low numbers of families found in the real hatchery samples were not due to random grouping of individuals, but should be considered significant (Hansen and Jensen 2005). In a similar study, Hansen et al. (2006) reported fewer numbers of half- and full-sib families in hatchery samples compared to the river counterparts in Catla catla.

In conclusion, we have characterized the population genetic structure of the founder stocks of $L$. rohita broodbank originated from three major river sources. These three rivers are considered the principal sources of the Indian major carps. So, the samples are representative of the species from Bangladesh. We have detected genetic bottlenecks in all three river samples of the broodbank collections meaning that the populations apparently have experienced drastic reduction in the recent past. The numbers of families in the sample of all three river were also low indicating a close relationship among the individuals which is not positive for a founder stock. Therefore, it is recommended to collect new batches of fish from various locations of the respective rivers that may broaden the genetic variability of the base population of the brood bank. As some negative points have been exposed from this study, it is strongly recommended to 
analyze at least 100 fish from each of the rivers with fifteen microsatellite DNA markers to obtain more precise information on genetic status of the brood bank stocks of L. rohita. This genetic data would serve as baseline information of the brood bank collections and enable efficient monitoring of the impact of natural and/or human interferences on the river populations of L. rohita in future.

\begin{abstract}
Abbreviations
Ar: allelic richness; C: celsius; DNA: deoxy ribonucleic acids; dNTPs: deoxy ribonucleotide triphosphates; DoF: Department of Fisheries; FAO: Food and Agriculture Organization; FRSS: Fishery Resources Survey System; He: heterozygosity expected; Ho: heterozygosity observed; HWE: Hardy-Weinberg expectation; IAM: infinite allele model; $\mathrm{MgCl}_{2}$ : magnesium chloride; $\mathrm{mM}$ : millimolar; $\mu$ M: micro-molar; $\mu$ l: microliter; MCMC: Monte Carlo Markov Chain; M: molar; PCR: polymerase chain reaction; PIC: polymorphic information content; RFLP: restriction fragment length polymorphism; RAPD: random amplified polymorphic dna; SMM: stepwise mutation model; TPM: two-phase model.
\end{abstract}

\section{Authors' contributions}

$A U, A B$ and $M N I$ collected samples, carried out the molecular genetic studies, participated in the genotyping and statistical analysis and drafted the manuscript. MSA planned the project and supervised all the activities of the three authors and helped to draft the manuscript. All authors read and approved the final manuscript.

\section{Acknowledgements}

The Brood bank Establishment Project (2nd Phase) of the Department of Fisheries, Ministry of Fisheries and Livestock for providing fund and fish samples.

\section{Competing interests}

The authors declare that they have no competing interests.

Received: 9 August 2015 Accepted: 30 November 2015 Published online: 14 December 2015

\section{References}

Abdul-Muneer PM (2014) Application of microsatellite markers in conservation genetics and fisheries management: recent advances in population structure analysis and conservation strategies. Genet Res Int. http://www. dx.doi.org/10.1155/2014/691759. Accessed 10 July 2015

Alam MS, Jahan M, Hossain MM, Islam MS (2009) Population genetic structure of three major river populations of rohu, Labeo rohita (Cyprinidae:Cypriniformes) using microsatellite DNA markers. Genes Genom 31:43-51

Azadi MA, Arshad-ul-Alam M (2012) Spawn fishery of major carps (Catla catla, Labeo rohita, Cirrhinus cirrhosus, and Labeo calbasu) of the river Halda. Book of Abstract. Fifth Fisheries Conference and Research Fair 2012. Dhaka, Bangladesh

Balloux F, Lugon-Moulin N (2002) The estimation of population differentiation with microsatellite markers. Molec Ecol 11:155-165

Basak A, Ullah A, Islam MN, Alam MS (2014) Genetic characterization of brood bank collections of the Indian Major Carp Catla catla (Hamilton) (Cyprinidae:Cypriniformes) by microsatellite DNA markers. J Anim Plant Sci 24(6):1786-1794

Blouin MS (2003) DNA-based methods for pedigree reconstruction and kinship analysis in natural populations. Trend Ecol Evol 18:503-511

Botstein D, White RL, Skolnick M, David R (1980) Construction of a genetic linkage map in man using restriction fragment length polymorphisms. Am J Hum Genet 32:314-331

Cornuet JM, Luikart G (1996) Description and power analysis of two tests for detecting recent population bottlenecks from allele frequency data. Genetics 144:2001-2014

Das P, Barat A, Meher PK, Ray PP, Majumdar D (2005) Isolation and characterization of polymorphic microsatellites in Labeo rohita and their cross-species amplification in related species. Molec Ecol Notes 5:231-233
Earl DA, vonHoldt BM (2012) Structure harvester: a website for visualizing STRUCTURE output and implementing the Evano method. Conserv Genet Resour 4(2):359-361

Evanno G, Regnaut S, Goudet J (2005) Detecting the number of clusters of individuals using the software STRUCTURE: a simulation study. Molec Ecol 14:2611-2620

Falush D, Stephens M, Pritchard JK (2003) Inference of population structure using multilocus genotype data: linked loci and correlated allele frequencies. Genetics 164(4):1567-1587

FAO (2012) FAO Yearbook, Fishery and Aquaculture Statistics 2010. Food and Agriculture Organization of the United Nations, Rome, p 78

FRSS (2003) Fisheries Statistical Yearbook of Bangladesh (2001-2002), vol 19. Fisheries Resources Survey System, Department of Fisheries, Bangladesh, p 41

FRSS (2012) Fisheries Statistical Yearbook of Bangladesh (2010-2011), vol 28. Fisheries Resources Survey System, Department of Fisheries, Bangladesh, p 46

Goudet J (2001) FSTAT Version 1.2: a computer program to calculate F-statistics. J Hered 86:485-486. FSTAT 2.9.3.2 [Software]. http://www2.unil.ch/ popgen/softwares/fstat.htm

Guo S, Thompson E (1992) Performing the exact test of Hardy-Weinberg proportion from multiple alleles. Biometrics 48:361-372

Hale ML, Burg TM, Steeves TE (2012) Sampling for microsatellite based population genetic studies: 25 to 30 individuals per population is enough to accurately estimate allele frequencies. PLoS One 7(9):e45170

Hansen MM, Jensen LF (2005) Sibship within samples of brown trout (Salmo trutta) and implications for supportive breeding. Conserv Genet 6:297-305

Hansen MM, Nielsen EE, Ruzzante DE, Bouza C, Mensberg K-LD (2000) Genetic monitoring of supportive breeding in brown trout (Salmo trutta L.) using microsatellite DNA markers. Can J Fish Aquat Sci 57:2130-2139

Hansen MM, Simonsen V, Mensberg KLD, Sarder MRI, Alam (2006) Loss of genetic variation in hatchery-reared Indian major carp, Catla catla. J Fish Biol 69(Suppl. B):229-241

Hasanat MA, Mollah MFA, Alam MS (2014) Assessment of genetic diversity in wild and hatchery populations of mrigal Cirrhinus cirrhosus (HamiltonBuchanan) using allozyme markers. Int J Fish Aquat Stud 1(4):24-31

Hussain MG, Mazid MA (2002) Genetic status and improvement strategies for endemic and exotic carps of Bangladesh. In: Penman DJ, Hussain MG, McAndrew BJ, Mazid MA (eds) Proceedings of a workshop on Genetic Management and Improvement Strategies for Exotic Carps in Asia, Dhaka, Bangladesh, pp 9-27, 12-14 Feb 2002

Islam MS, Alam MS (2004) Randomly amplified polymorphic DNA analysis of four different populations of the Indian major carp, Labeo rohita (Hamilton). J Appl Ichthyol 20:407-412

Jones OR, Wang J (2010) COLONY: a program for parentage and sibship inference from multilocus genotype data. Molec Ecol Resour 10:551-555

Kalinowski ST, Taper ML, Marshall TC (2007) Revising how the computer program CERVUS accommodates genotyping error increases success in paternity assignment. Molec Ecol 16(5):1099-1106

Nei M (1972) Genetic distance populations. Am Nat 106:283-292

Nei M (1987) Molecular evolutionary genetics. Columbia University Press, New York, p 512

Nielsen E, Arvebach L, Kotlicki P (2006) Hybridlab (version 1.0): a program for generating simulated hybrids from population samples. Molec Ecol Notes 6:971-973

O'Connell M, Wright JM (1997) Microsatellite DNA in fishes. Rev Fish Biol Fish 7:331-363

Pritchard JK, Stephens M, Donnelly P (2000) Inference of population structure using multilocus genotype data. Genetics 155:945-959

Rahman MM (2008) Capture-based aquaculture of wild-caught Indian major carps in the Ganges Region of Bangladesh. In: Lovatelli A, Holthus PF (eds) Capture based aquaculture. Global overview. FAO Fisheries Technical Paper. No. 508. FAO, Rome, pp 127-140

Rice WR (1989) Analyzing tables of statistical tests. Evolution 43:223-225

Rousset F (2008) GENEPOP'007: A complete re-implementation of the GENEPOP software for Windows and Linux. Molec Ecol Resour 8:103-106

Saha D, Nahiduzzaman M, Akter S, Hossain MAR, Alam MS (2010) Bottleneck in the endangered kalibaus, Labeo calbasu (Cyprinidae: Cypriniformes) populations in Bangladesh revealed by microsatellite DNA marker analysis. Genes Genom 32:47-53 
Sahoo L, Sahu BP, Das SP, Swain SK, Bej D, Patel A, Jayasankar P, Das P (2014) Limited genetic differentiation in Labeo rohita (Hamilton 1822) populations as revealed by microsatellite markers. Biochem Syst Ecol 57:427-431 Simonsen V, Hansen MM, Mensberg K-LD, Sarder Rl, Alam MS (2005) Widespread hybridization among species of Indian major carps in hatcheries, but not in the wild. J Fish Biol 67:794-808

Talwar PK, Jhingran AG (1991) Inland fishes of India and adjacent countries, vol I. Oxford and IBH Publishing C. Pvt. Ltd., New Delhi, p 541

Tautz D (1989) Hypervariability of simple sequences as a general source for polymorphic DNA markers. Nucleic Acids Res 17:6463-6471

Tave D (1993) Genetics for fish hatchery managers, 2nd edn. Van Nostrand Reinhold, New York, p 436 van Oosterhout CV, Hutchinson WF, Wills DPM, Shipley P (2004) MICRO-

CHECKER: software for identifying and correcting genotyping errors in microsatellite data. Molec Ecol Notes 4:535-538

Vandewoestijne S, Schtickzelle N, Baguette M (2008) Positive correlation between genetic diversity and fitness in a large, well-connected metapopulation. BMC Biol 6:46

Wang J (2004) Sibship reconstruction from genetic data with typing errors. Genetics 166:1963-1979

Weir BS, Cockerham CC (1984) Estimating F-statistics for the analysis of population structure. Evolution 38:1358-1370

\section{Submit your manuscript to a SpringerOpen ${ }^{\circ}$ journal and benefit from:}

- Convenient online submission

- Rigorous peer review

- Immediate publication on acceptance

- Open access: articles freely available online

- High visibility within the field

- Retaining the copyright to your article

Submit your next manuscript at $\boldsymbol{~ s p r i n g e r o p e n . c o m ~}$ 